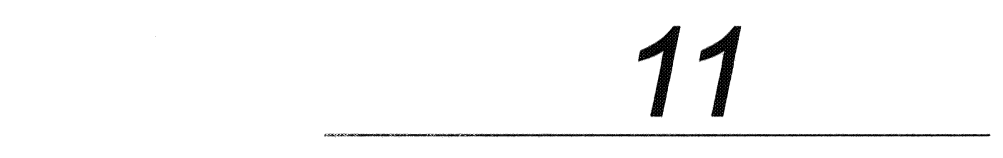

\title{
Using SWMM EXTRAN to Simulate WWTP Hydraulics
}

\author{
Derek Wride, Carl Chan, Ben Gamble, Joseph Koran and Susan \\ Moisio
}

SWMM EXTRAN has been successfully deployed to simulate wastewater treatment plant hydraulics at the seven major wastewater treatment plants (WWTPs) owned and operated by the Metropolitan Sewer District of Greater Cincinnati (MSDGC). An approximate 42,000-node SWMM model has been built and calibrated to represent the system wide wastewater collection system in Hamilton County, Ohio. Without the treatment plant hydraulics included, collection system boundary conditions are typically fixed or represented as a simplified time-variable tailwater. By including the WWTP hydraulics, the downstream boundary condition has been effectively moved to the plant outfalls and the WWTP facilities have been simulated as model components. Including WWTP hydraulics allows for a more integrated understanding of wastewater system performance during wet-weather conditions. This chapter presents the methods that were used to represent the WWTP facilities in EXTRAN and to successfully simulate the WWTP hydraulics.

\subsection{Introduction}

Hydraulic/hydrologic computer modeling is a tool commonly used to help sewer agencies understand the hydraulic performance of their wastewater collection systems. The MSDGC has developed a computer model of its wastewater collection system referred to as the System Wide Model (SWM)

Wride, D., C.C. Chan, B. Gamble, J. Koran and S. Moisio. 2004. "Using SWMM EXTRAN to Simulate WWTP Hydraulics." Journal of Water Management Modeling R220-11. doi: 10.14796/JWMM.R220-11.

(C) CHI 2004 www.chijournal.org ISSN: 2292-6062 (Formerly in Innovative Modeling of Urban Water Systems. ISBN: 0-9683681-9-0) 
in order to help achieve its various objectives. The model includes sanitary sewers with a diameter of 12 in. $(305 \mathrm{~mm})$ or greater and combined sewers with a diameter of 18 in. $(457 \mathrm{~mm}$ ) or greater, with a total of more than 42,000 pipes. The model will be used to characterize and evaluate nearly 90 sanitary sewer overflows (SSOs) and approximately 230 combined sewer overflows (CSOs), address wet-weather problems related to SSOs and CSOs, and ultimately used for real-time sewer system control evaluations. The approximately 3,000 miles $(4,824 \mathrm{~km})$ of sewer included in the model service approximately 800,000 residents covering close to 400 square miles $\left(1,033 \mathrm{~km}^{2}\right)$, including the entire City of Cincinnati and large portions of Hamilton County, Ohio.

The MSDGC service area is divided into smaller drainage basins at several different levels in order to organize and manage the model input datasets. The three major drainage basins define the broadest level of basin delineation, which is then delineated into $18 \mathrm{sub}$-basins. Figure 11.1 illustrates the delineation of the three major drainage basins. Figure 11.2 illustrates the delineation of the sub-basins. The 18 sub-basins have been subdivided into 304 sewershed areas to provide a finer level of detail for project execution. Figure 11.3 shows the sewersheds across the System Wide Model study area. Flow monitoring and modeling were organized at the sewershed level. The 304 sewersheds were further delineated into more than 26,600 catchments, which represent the smallest level of area tributary to the model. Input flows to the model were organized on the catchment level. The collection system models were organized on the sewershed-level.

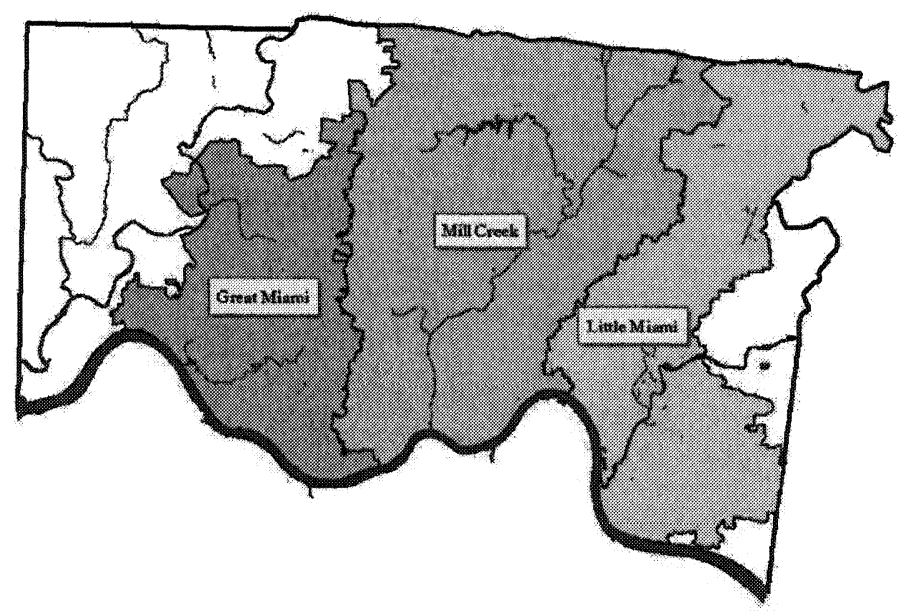

Figure 11.1 Major drainage basins in MSDGC service area. 


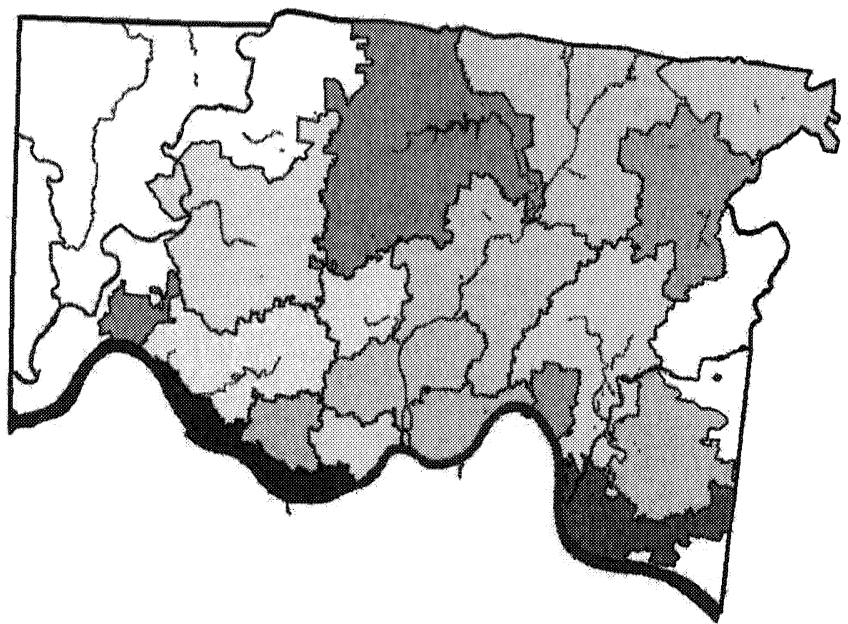

Figure 11.2 Sub-basin delineations in MSDGC service area.

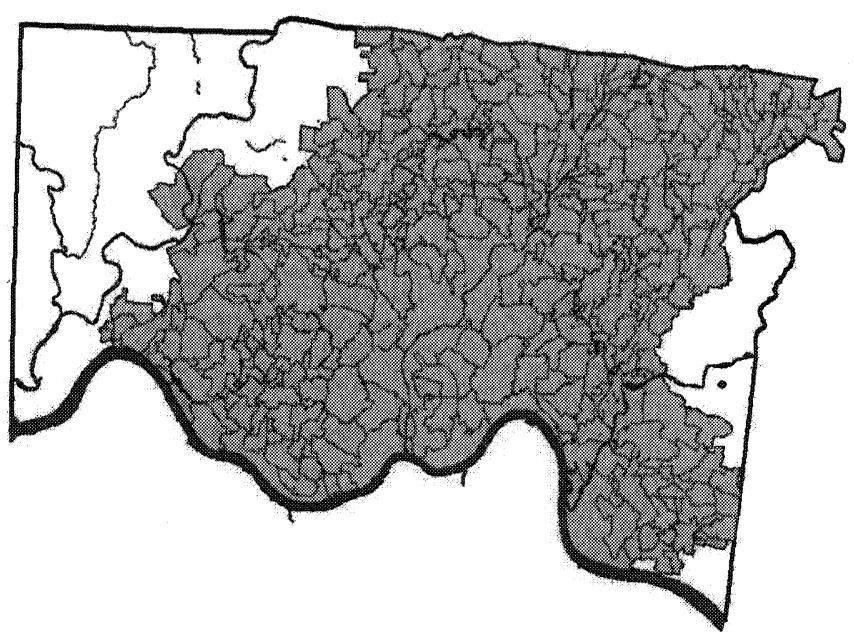

Figure 11.3 Sewershed delineations in MSDGC service area.

As part of the SWM, the hydraulics for the seven major wastewater treatment plants (WWTP) were incorporated into the model. The capability to simulate the hydraulic gradient and flow rate through the WWTP facilities was added. These facilities were originally represented as fixed and/or time variable boundary conditions to the calibrated collection system model. The models were modified to effectively relocate the model boundary conditions to the plant 


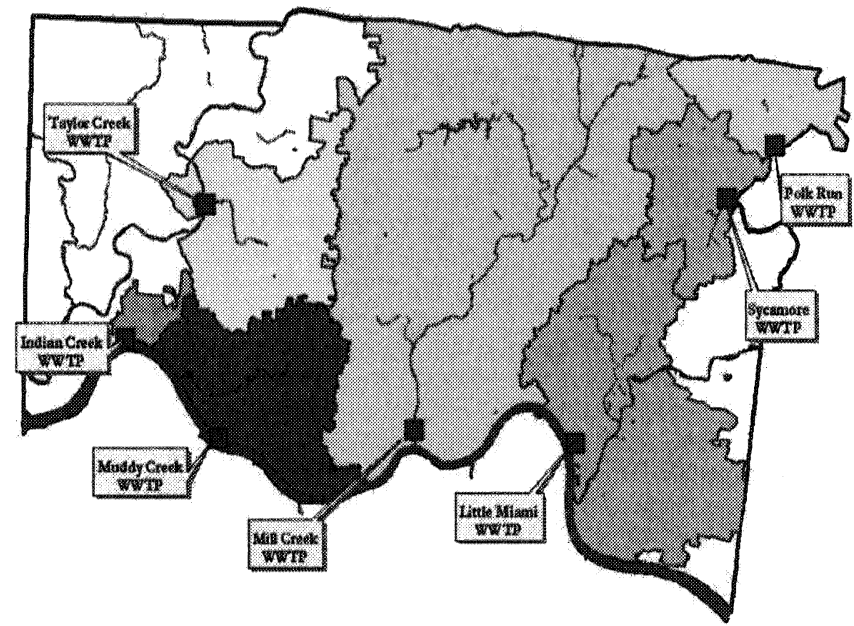

Figure 11.4 Locations of seven major MSD WWTPs and tributary areas.

outfalls and incorporate the WWTP facilities as simulated model components. Water quality was not included. Only the plant hydraulics were modeled. The seven WWTPs modeled are the Mill Creek, Little Miami, Muddy Creek, Sycamore, Polk Run, Taylor Creek, and Indian Creek WWTPs. They vary in peak wet weather capacity from $6 \mathrm{mgd}(263 \mathrm{~L} / \mathrm{s})$ at the Indian Creek WWTP to $430 \mathrm{mgd}(18,812 \mathrm{~L} / \mathrm{s})$ at the Mill Creek WWTP. Figure 11.4 illustrates the locations of the seven major WWTPs in the MSD drainage area. Including the WWTP hydraulics allows for a more integrated understanding of the wastewater system performance during wet-weather conditions. The model is intended to be used as a planning and analysis tool. The general approach to modeling the WWTP hydraulics is explained and results are presented to illustrate the level of success achieved in simulating the WWTP hydraulics.

\subsection{Modeling Approach}

The EPA StormWater Management Model (SWMM) (Huber and Dickinson, 1992) was the software used to simulate the hydrologic and hydraulic components of the model. The SWMM RUNOFF module was used to model the hydrology while the SWMM EXTRAN module was used to simulate the hydraulics of the system. Both the collection system model and the WWTP hydraulics were modeled using EXTRAN. 
Simplified models of the WWTPs were first built and initially executed with dry-weather flow loadings. The initial models included a simplified model from the headworks through the treatment process and out to the receiving waters at the outfall. As the simplified models proved stable, they were then expanded and refined and loaded with wet-weather flows (WWF). The WWTP model was expanded by adding the portion of the collection system immediately upstream of the headworks that extended to the first upstream collection system flow meter where backwater effects did not occur or were minor. This allowed for more accurately loading the model with flow data from the upstream flow meters since the flow recorded at the sites were not influenced by backup conditions. Five of the seven WWTP models were modeled and calibrated using three different historical rainfall events, while the Little Miami and Sycamore WWTP models used two events.

The availability and quality of data used to calibrate the models varied between the different WWTPs. The data to build the models was based on available plant drawings, profiles, plant logs, flow charts, and interviews and discussions with various treatment plant personnel. The WWTP models were developed to represent the configuration of the WWTPs as they existing during the two different flow monitoring periods used to calibrate the collection system. For the Mill Creek WWTP, the calibration events were selected from the collection system calibration events, which occurred between February and June 2001. For all other WWTP models, the calibration events were selected from the calibration events for their respective upstream collection system calibrations, which occurred between February and May 2002. The following are the different types of data that were available to calibrate the WWTP models:

1. WWTP effluent time series $(\mathrm{h})$,

2. WWTP effluent volume (d),

3. WWTP influent flow,

4. bypass flow/volume,

5. collection system flow and level in vicinity of WWTP, and

6. design water elevation at different components of the treatment process.

Many of the more complex hydraulic simulation features of SWMM EXTRAN were used to represent the WWTP hydraulic elements, including weirs, orifices, variable and 2-stage pumping, storage, and time-varying orifices. Many challenges surfaced in creating models in which these more complex features are required to properly simulate the WWTP hydraulics, often involving the associated elements to be located directly in series in the WWTP portion of the modeled network. In general, unstable weirs were replaced with 
orifices. Pumping schemes involving multiple pumps were replaced with simplified pump schemes, and, where possible, short pipes were avoided. The two most common adjustments in the model were changing weirs to orifices and simplifying the pumping scheme. The simulation time step for the models was either one, three, or five-seconds.

The success of the models was based on the ability of SWMM EXTRAN to model the treatment process hydraulics without significant instabilities while producing model results that compared favorably to available plant data. Influent flow and bypass flows (where applicable) were available for most of the plants. Some water elevation data was available upstream of the plant headworks of most plants. Only the Mill Creek and Little Miami WWTPs had flow available at a point within the treatment process.

\subsection{Model Results}

\subsubsection{Mill Creek WWTP}

The Mill Creek WWTP is the largest of the seven major MSD WWTPs with a permitted average flow of $130 \mathrm{mgd}(5,687 \mathrm{~L} / \mathrm{s})$, and can treat a peak flow of $430 \mathrm{mgd}(18,812 \mathrm{~L} / \mathrm{s})$. It treats the flow from the Mill Creek Drainage Basin and is located approximately two miles $(3.2 \mathrm{~km})$ from downtown Cincinnati. It's effluent is discharged to the Ohio River. Figure 11.5 is an aerial photo of the Mill Creek WWTP. Figure 11.6 illustrates a schematic representation of the Mill Creek WWTP, which is typical of all seven major WWTPs, with some variation, as noted in the subsequent schematics views of the WWTPs.

The initial modeling of the Mill Creek WWTP involved three weirs; one on the effluent side of the primary, one on the effluent side of the aeration tanks, and one on the effluent side of the secondary settling tanks. Only the weir simulated on the effluent side of the primary settling tanks was changed to an equivalent orifice to help improve the model stability.

The Mill Creek WWTP has a North and a South Pump Station at the headworks. Nine 2-stage pumps are found in the North Pump Station while an additional three pumps are located in the South Pump Station. Instead of using separate H-cards for each of the twelve pumps, the modeling scheme for the Mill Creek WWTP was simplified to one set of parameters on the EXTRAN Hcards. This approach simplified the model while maintaining a representative pumping scheme. Figure 11.7 illustrates a schematic of the EXTRAN model with the major components labeled. 


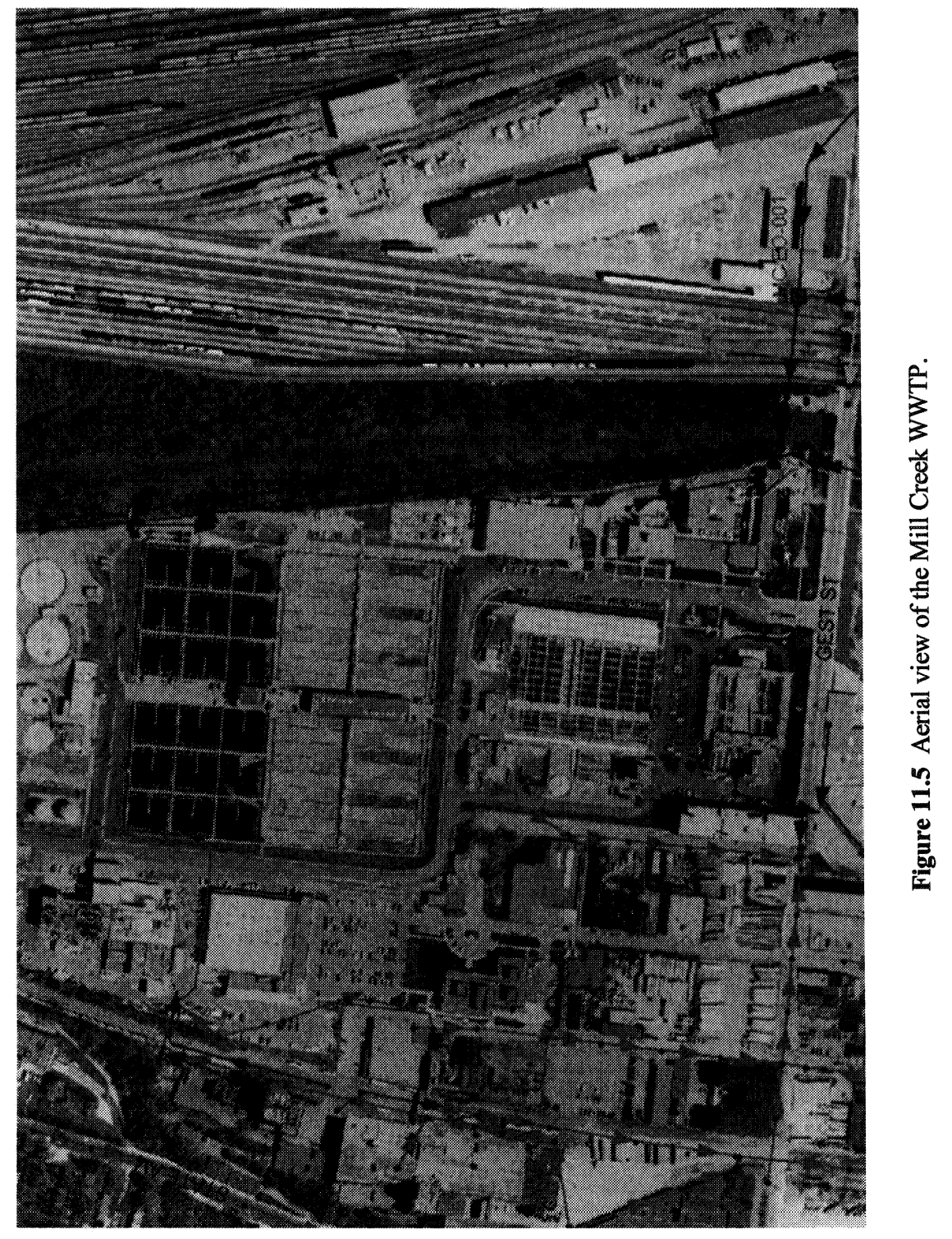




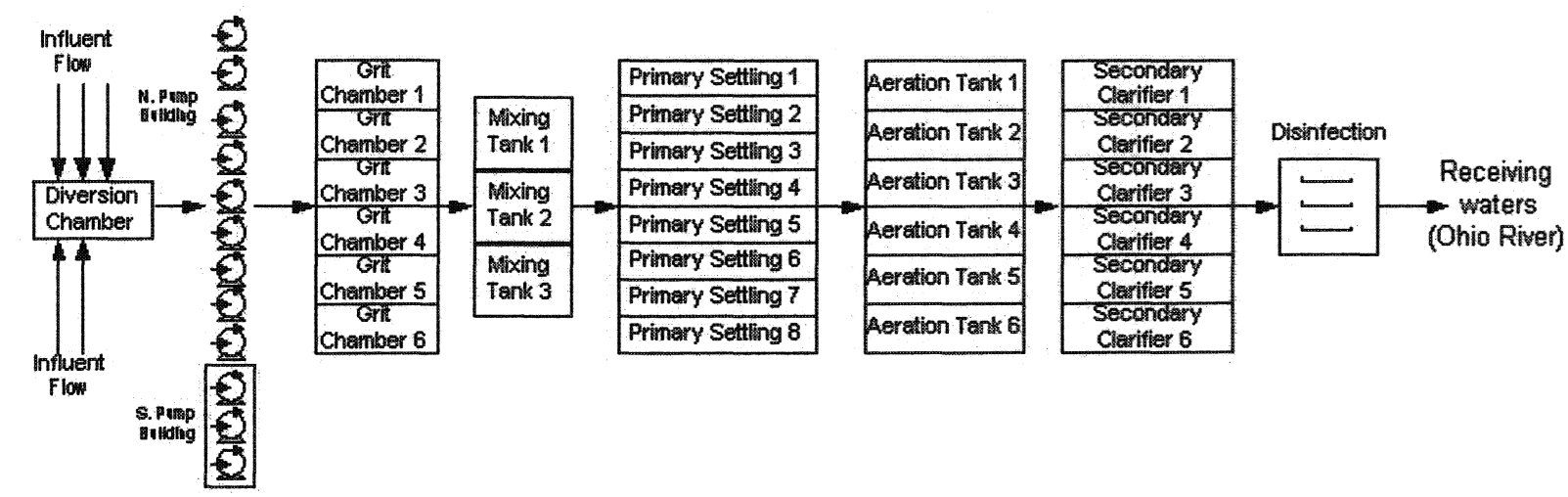

Figure 11.6 Schematic view of the Mill Creek WWTP.

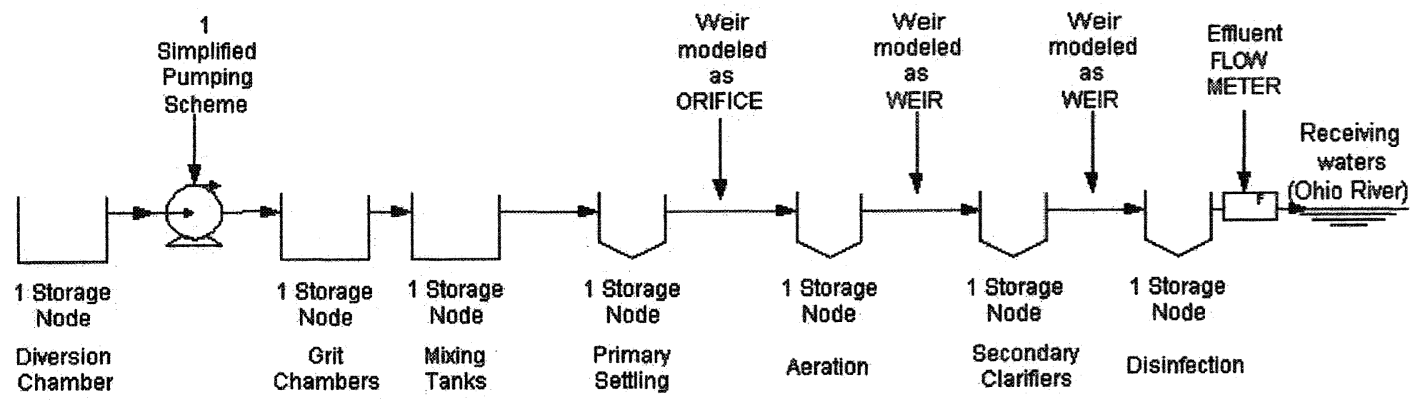

Figure 11.7 EXTRAN schematic of the Mill Creek WWTP Model. 
Three wet-weather flow events were used to calibrate the model. The EXTRAN output files for all three calibration events showed an overall continuity error of "NaN" (Not a Number) before the mentioned changes were made. Table 11.1 shows the overall continuity errors before and after the changes to the one weir at the effluent side of the primary settling tanks and the pumping scheme. Table 11.2 shows the comparison between the observed and the calibrated model peak secondary effluent flow rates.

Table 11.1 Overall continuity errors for the Mill Creek WWTP Model.

\begin{tabular}{lcc}
\hline Calibration Event & \multicolumn{2}{c}{ Overall Continuity Error $^{1}$} \\
\hline & Before Changes $^{2}$ & After Changes \\
May 07, 2001 event & $\mathrm{NaN}^{3}$ & -0.152 \\
May 17, 2001 event & $\mathrm{NaN}^{3}$ & -0.391 \\
May 18,2001 event & $\mathrm{NaN}^{3}$ & -0.391 \\
\hline Note: Continuity errors are as they are reported in the respective EXTRAN output files. \\
${ }^{2}$ Note: The changes made are presented earlier in this chapter. \\
NaN = "Not a Number", signifying an unreasonable calculation of the continuity error.
\end{tabular}

Table 11.2 Calibration results for the Mill Creek WWTP Model.

\begin{tabular}{ccc}
\hline Calibration Event & \multicolumn{1}{c}{ Difference (\%) } \\
\hline & Volume $^{1}$ & Peak Flow $^{1}$ \\
May 07, 2001 event & 11 & 13 \\
May 17, 2001 event & 34 & 5 \\
May 18, 2001 event & 19 & -11 \\
\hline
\end{tabular}

${ }^{1}$ Based on secondary peak effluent flow rate.

The continuity errors for the different calibration events illustrate that, overall, model stability was achieved. Some localized model instability existed where the hydraulic grade line was observed to oscillate some, but did not propagate downstream. This was observed mostly at the pumping site. The calibration of the peak flow rates represented a successful match as the difference between the observed and simulated peak flow rates were varied between 5 and $13 \%$. A view of one of the calibration plots shows that not all of the significant fluctuations in the observed flow were simulated in the model. The fluctuations in the observed flow data is likely attributable to fluctuations 
in the operation of the pumps at the headworks. The pumping scheme described in the model is according to the overall pumping strategy and does not necessarily reflect the actual operation of the pumps for the specific simulation dates, as pumping logs were not available. Figure 11.8 illustrates an example where the peak and volume calibrations were acceptable, but some significant fluctuations in the observed flow were not captured by the model. This affect is also found in some of the other calibration plots for the other WWTP models.

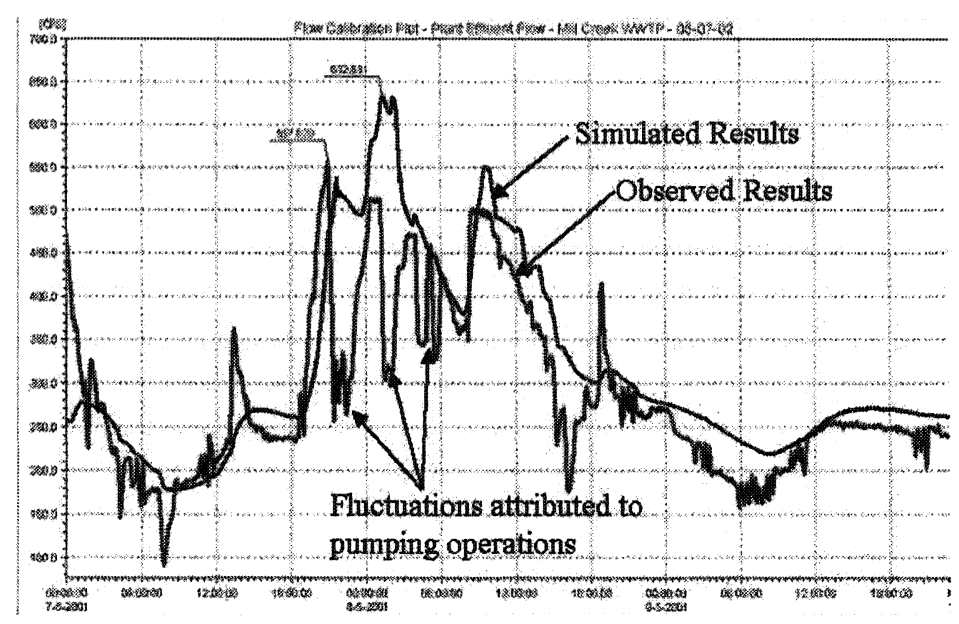

Figure 11.8 Calibration plot for May 7, 2001 event for Mill Creek WWTP Model.

\subsubsection{Muddy Creek WWTP}

The Muddy Creek WWTP has a permitted average flow of $15 \mathrm{mgd}(656 \mathrm{~L} / \mathrm{s})$ and treats a peak flow of about $22 \mathrm{mgd}(963 \mathrm{~L} / \mathrm{s})$. The Muddy Creek WWTP is located approximately 10 miles $(16 \mathrm{~km})$ west of downtown Cincinnati and discharges into the nearby Ohio River. Figure 11.9 is an aerial view of the Muddy Creek WWTP with the Ohio River shown in the bottom left corner. To obtain the overall model stability, three of the four weirs in the initial model setup were changed to orifices in EXTRAN. Daily plant effluent volume amounts were available for calibration purposes. Also, good water level data was available in the collection system immediately upstream of the plant headworks. This was the primary calibration data for the Muddy Creek WWTP. Table 11.3 shows the overall continuity errors for the three calibration events. Table 11.4 


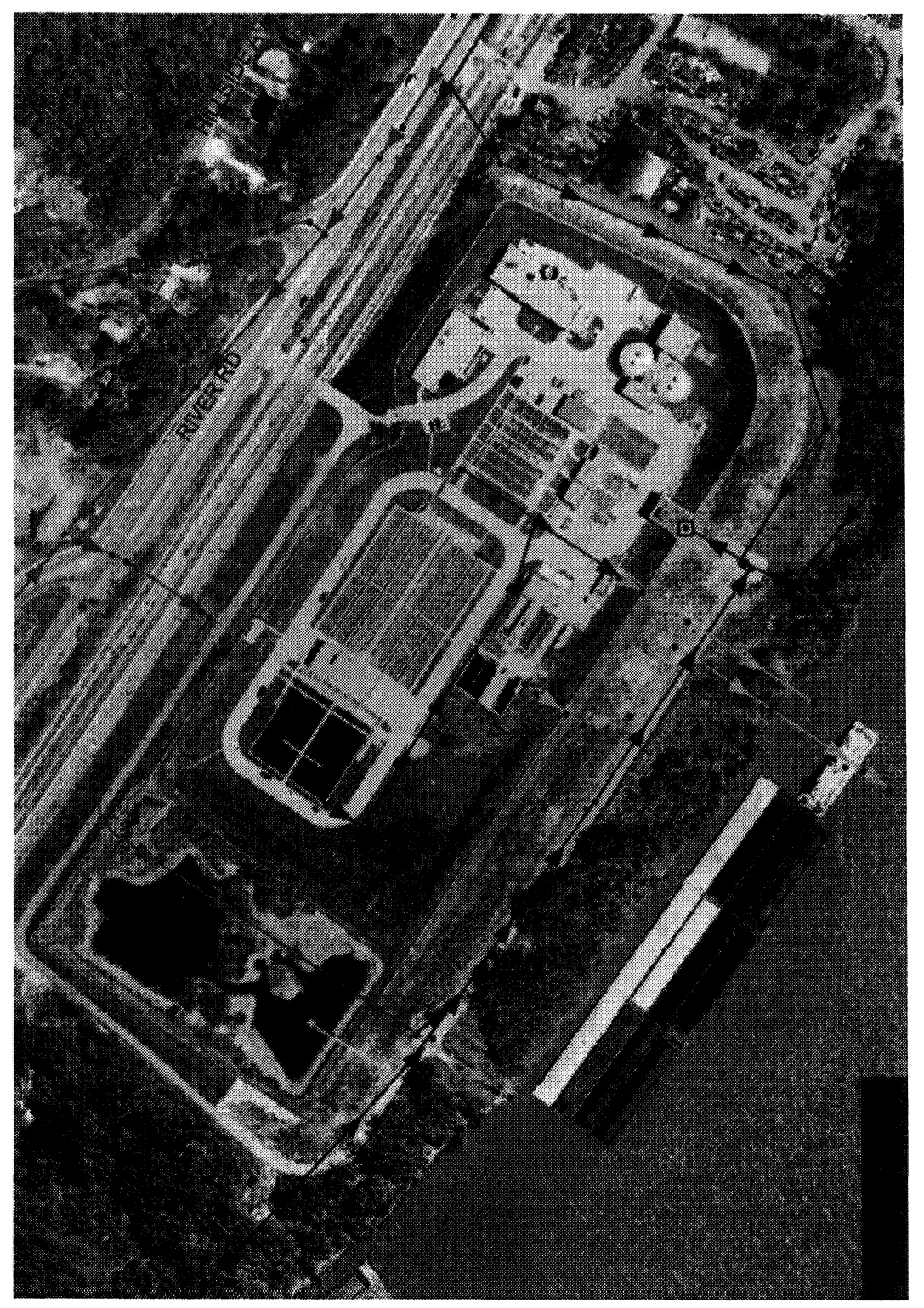

 
shows the flow and volume calibration data for the Muddy Creek WWTP. No peak plant effluent flow data was available for calibration.

Table 11.3 Overall continuity errors for the Muddy Creek WWTP Model.

\begin{tabular}{lcc}
\hline Calibration Event & \multicolumn{2}{c}{ Overall Continuity Error $^{1}$} \\
\hline & Before Changes ${ }^{2}$ & After Changes \\
& & -4.65 \\
February 19,2002 & -4.576 & -0.82 \\
March 9, 2002 & -0.735 & -3.11 \\
April 3, 2002 & $\mathrm{NaN}^{3}$ & \\
1Note: Continuity errors are as they are reported in the respective EXTRAN output files. \\
${ }^{2}$ Note: The changes made are presented earlier in this chapter. \\
${ }^{3}$ NaN = "Not a Number", signifying an unreasonable calculation of the continuity error.
\end{tabular}

Table 11.4 Calibration results for the Muddy Creek WWTP Model.

\begin{tabular}{lcc}
\hline \multicolumn{1}{c}{ Calibration Event } & Difference (\%) \\
\hline & Volume & Peak Flow \\
February 19, 2002 & -1 & na \\
March 9, 2002 & -27 & na \\
April 3, 2002 & -29 & na \\
\hline
\end{tabular}

\subsubsection{Taylor Creek WWTP}

The Taylor Creek WWTP has a permitted average flow of $4 \mathrm{mgd}$ and treats a peak flow of about $10 \mathrm{mgd}(437 \mathrm{~L} / \mathrm{s})$. The Taylor Creek WWTP is located approximately 12 miles $(19 \mathrm{~km})$ northwest of downtown Cincinnati. Figure 11.10 is an aerial view of the Taylor Creek WWTP. Hourly plant effluent flow rates were taken from circular flow charts. Table 11.5 shows the volume calibration results.

Table 11.5 Calibration results for the Taylor Creek WWTP Model.

\begin{tabular}{lcc}
\hline \multicolumn{1}{c}{ Calibration Event } & \multicolumn{1}{c}{ Difference (\%) } \\
\hline & Volume & Peak Flow \\
February 1, 2002 & -17 & -9 \\
March 25, 2002 & -10 & 2 \\
April 21, 2002 & -5 & -15 \\
\hline
\end{tabular}




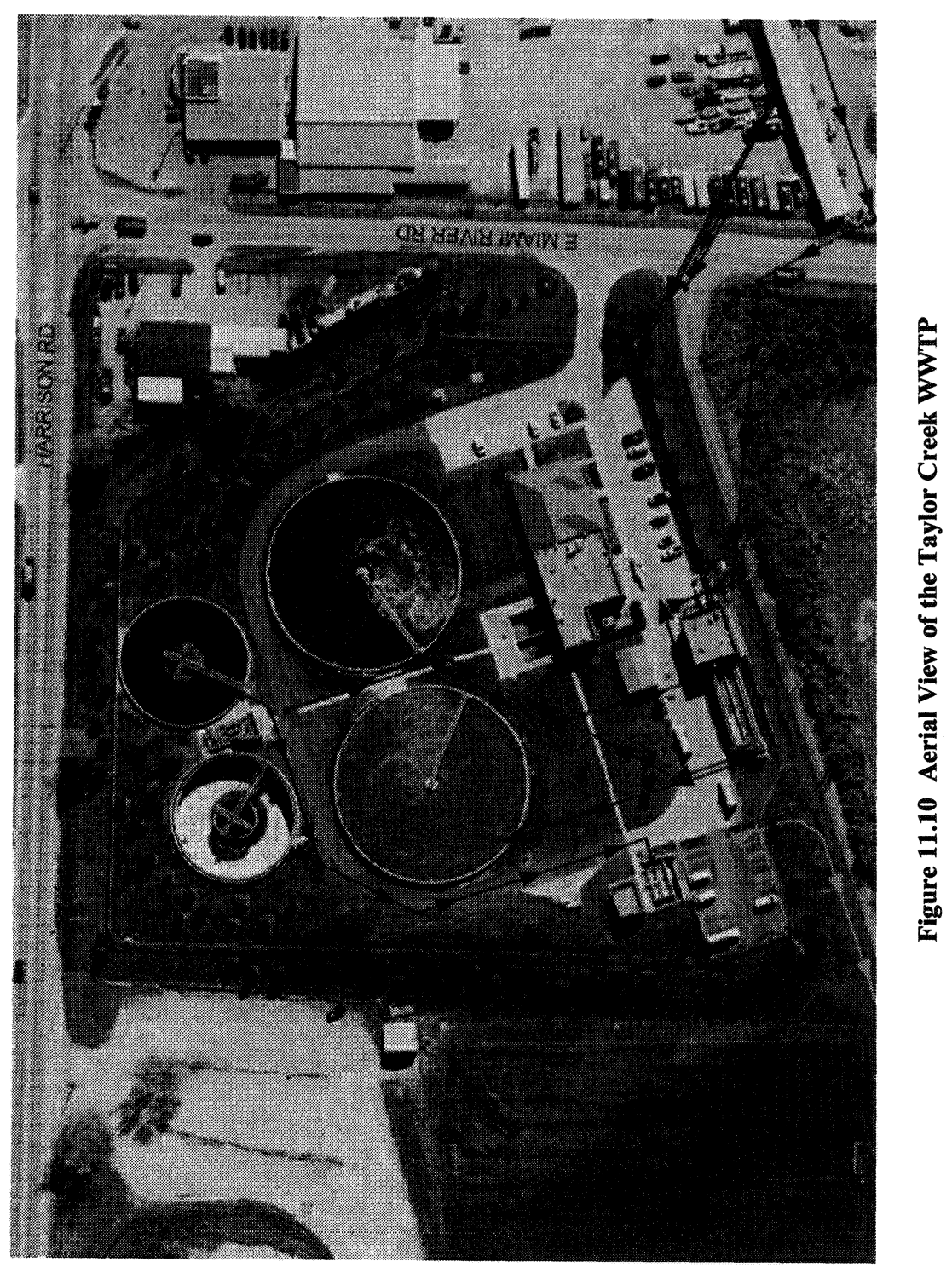




\subsubsection{Indian Creek WWTP}

The Indian Creek WWTP has a permitted average flow of $1.5 \mathrm{mgd}(66 \mathrm{~L} / \mathrm{s})$ and treats a peak flow of about $6 \mathrm{mgd}(263 \mathrm{~L} / \mathrm{s})$. The Indian Creek WWTP is located approximately 15 miles $(24 \mathrm{~km})$ west of downtown Cincinnati. Figure 11.11 is an aerial view of the Indian Creek WWTP. Hourly plant effluent flow rates were taken from circular flow charts. Table 11.6 shows the calibration results for the Indian Creek WWTP model.

Table 11.6 Calibration results for the Indian Creek WWTP Model.

\begin{tabular}{lcc}
\hline \multicolumn{1}{c}{ Calibration Event } & \multicolumn{3}{c}{ Difference (\%) } \\
\hline & Volume & Peak Flow \\
April 13, 2002 & 4 & 27 \\
April 19, 2002 & -47 & 21 \\
May 7, 2002 & 20 & -4 \\
\hline
\end{tabular}

\subsubsection{Sycamore WWTP}

The Sycamore WWTP has a permitted average flow of $6 \mathrm{mgd}(263 \mathrm{~L} / \mathrm{s})$ and can treat a peak flow of about $32 \mathrm{mgd}(1,400 \mathrm{~L} / \mathrm{s})$. The Sycamore WWTP is located approximately 14 miles $(23 \mathrm{~km})$ northeast of downtown Cincinnati. Figure 11.12 is an aerial view of the Sycamore WWTP. Hourly plant effluent flow rates were available for calibration. The Sycamore WWTP is the only major WWTP that includes a sand filtration component. Table 11.7 shows the calibration results for the Sycamore WWTP model.

Table 11.7 Calibration results for the Sycamore WWTP Model.

\begin{tabular}{ccc}
\hline Calibration Event & \multicolumn{3}{c}{ Difference (\%) } \\
\hline & Volume & Peak Flow \\
April 12, 2002 & 180 & 38 \\
April 21, 2002 & 70 & 1 \\
\hline
\end{tabular}




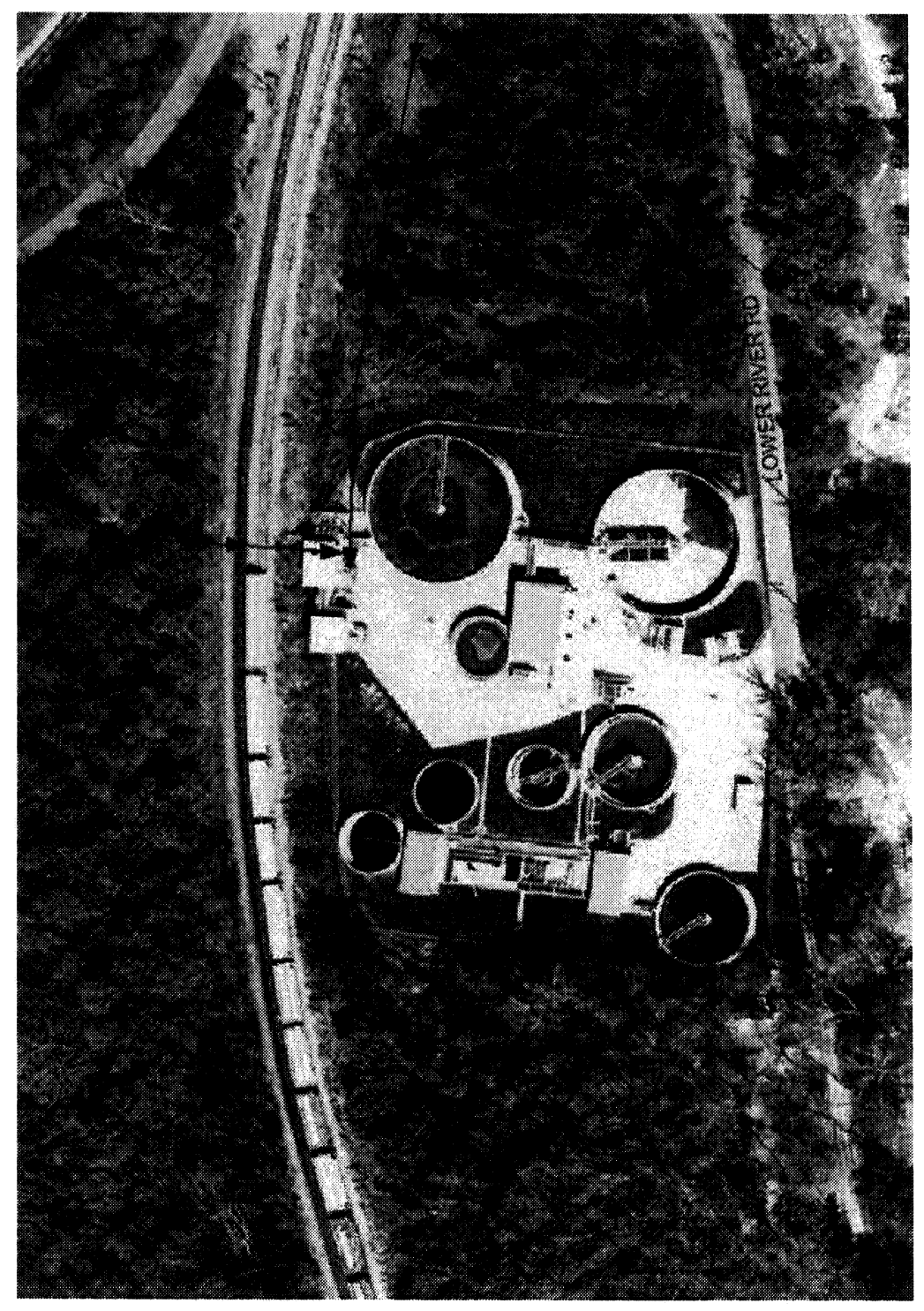

 


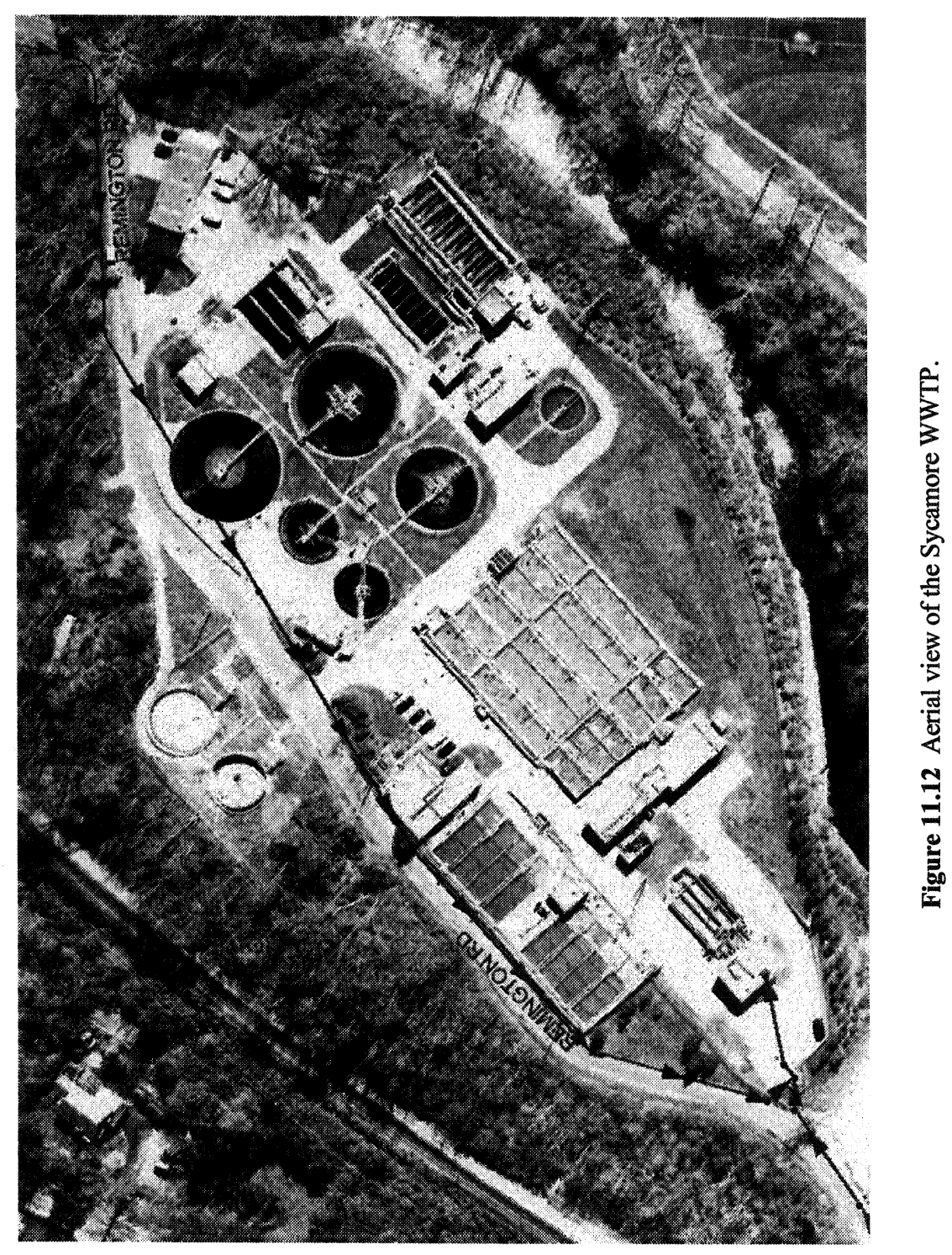




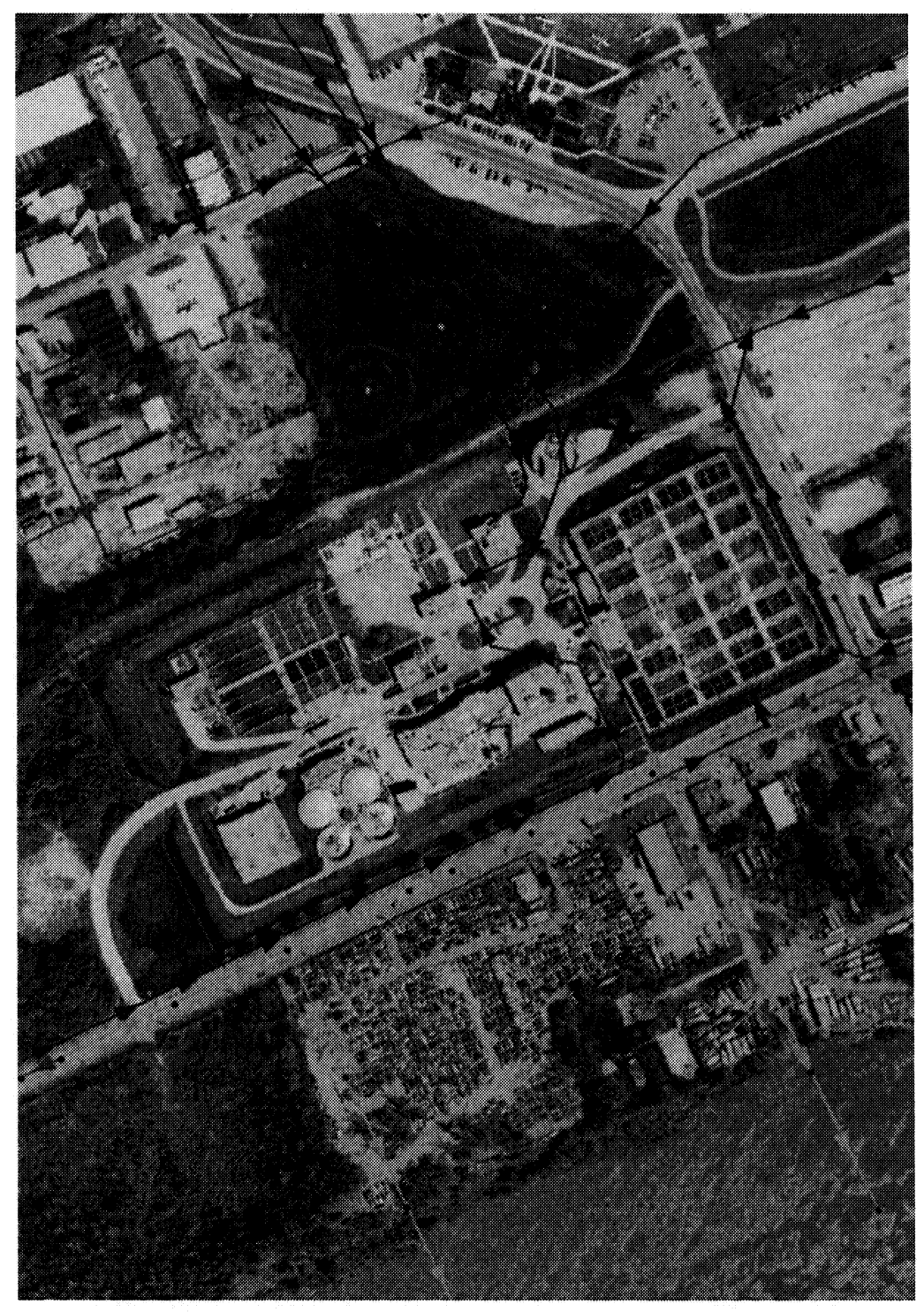

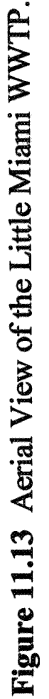




\subsubsection{Little Miami WWTP}

The Little Miami WWTP is the second largest of the seven major WWTPs and has an average flow of $38 \mathrm{mgd}(1,662 \mathrm{~L} / \mathrm{s})$ with the ability to treat a peak flow of about $94 \mathrm{mgd}(4,112 \mathrm{~L} / \mathrm{s})$. The Little Miami WWTP is located approximately 5.5 miles $(9 \mathrm{~km})$ east of downtown Cincinnati. Figure 11.13 is an aerial view of the Little MiamiWWTP. Hourly secondary effluent flow rates were used for calibration. Table 11.8 shows the calibration results for the Little Miami WWTP model.

Table 11.8 Calibration results for the Little Miami WWTP Model.

\begin{tabular}{lcc}
\hline Calibration Event & \multicolumn{2}{c}{ Difference (\%) } \\
\hline & Volume & Peak Flow \\
April 21, 2002 & -67 & -8 \\
May 12, 2002 & -61 & -20 \\
\hline
\end{tabular}

The modeling of the Little Miami WWTP proved to be the most challenging. Two separate pumping facilities exist at the headworks of the WWTP; the Four Mile Pump Station (newer) and the Little Miami Pump Station (older). The Four Mile Pump has five pumps, while the Little Miami Pump Station has nine pumps. One major interceptor sewer discharges to the Little Miami Pump Station while a major interceptor and trunk sewer discharge into the Four Mile Pump Station. The hydraulics are complicated by a connection between the two interceptor sewers that is gate-controlled. The pumping strategies of the two pump stations are somewhat irregular with no available pumping logs to understand actual operating conditions. The general pumping strategies were input into the model, but the model results indicate that fluctuations in the effluent flow rates were not accurately simulated by the model setup. The lack of actual pumping logs was the biggest factor in achieving satisfactory calibrations.

\subsubsection{Polk Run WWTP}

The Polk Run WWTP has a permitted average flow of $6 \mathrm{mgd}(263 \mathrm{~L} / \mathrm{s})$ and treats a peak flow of about $12 \mathrm{mgd}(525 \mathrm{~L} / \mathrm{s})$. The Polk Run WWTP is located approximately 16 miles $(26 \mathrm{~km})$ northeast of downtown Cincinnati. Figure 11.14 is an aerial view of the Polk Run WWTP. Hourly plant effluent flow rates were available for calibration. Table 11.9 shows the calibration results for the Polk Run WWTP model. 


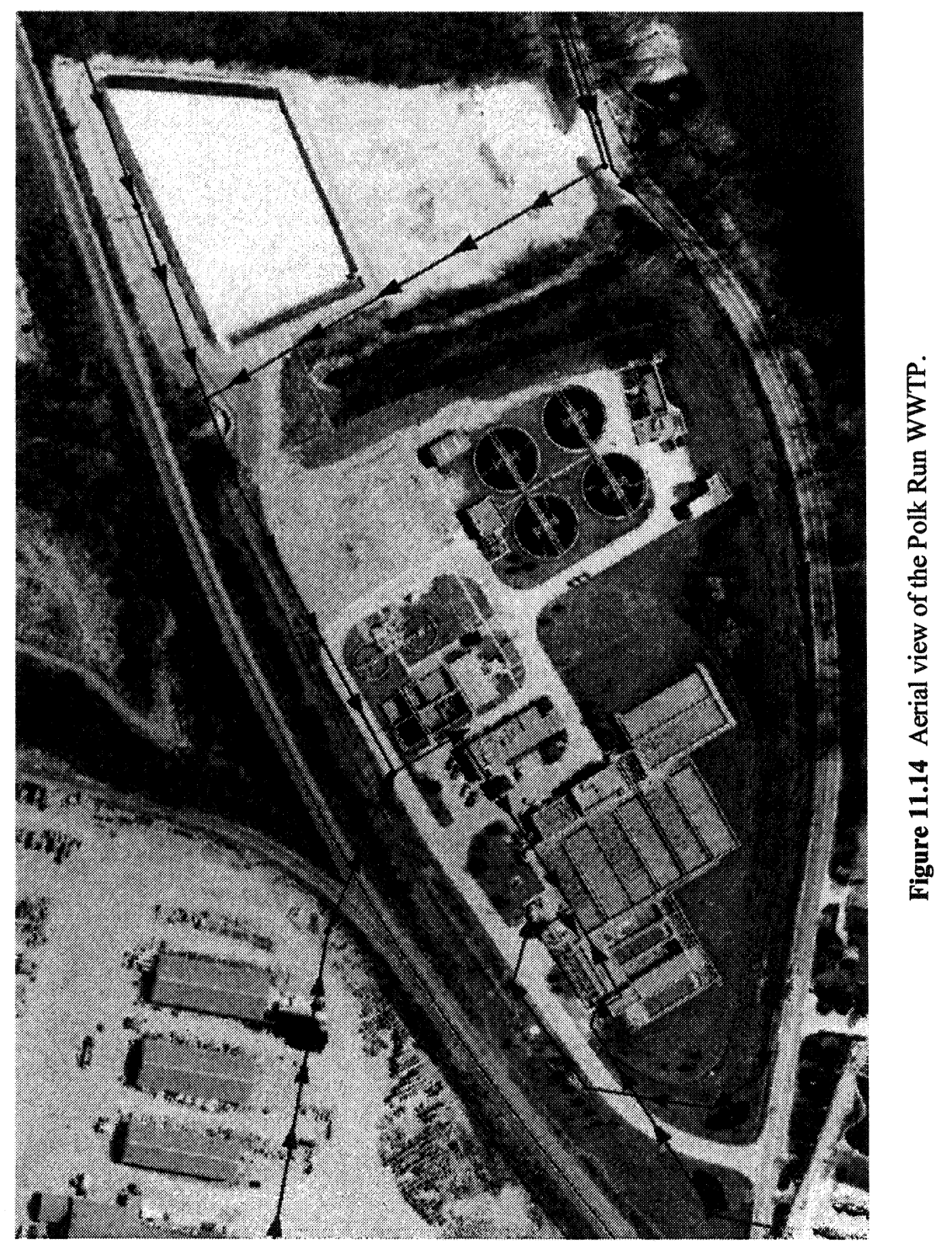


Table 11.9 Calibration results for the Polk Run WWTP Model.

\begin{tabular}{|c|c|c|}
\hline \multirow[t]{2}{*}{ Calibration Event } & \multicolumn{2}{|c|}{ Difference $(\%)$} \\
\hline & Volume & Peak Flow \\
\hline April 12, 2002 & 40 & -3 \\
\hline April 21, 2002 & 10 & 7 \\
\hline May 8, 2002 & 21 & 8 \\
\hline
\end{tabular}

\subsection{Summary and Conclusions}

SWMM EXTRAN has been successfully used to simulate the wastewater treatment plant hydraulics at the seven major wastewater treatment plants owned and operated by the Metropolitan Sewer District of Greater Cincinnati. The success was based on achieving overall model stability and by yielding model results that matched favorably to the observed data. The calibration results varied between the different WWTPs due to the availability of observed WWTP data, the quality of the available data, EXTRAN limitations, and the complexity of the models.

Overall model stability was achieved for each of the WWTP models. Only one calibration event for the Little Miami WWTP model was outside the normally accepted range for the continuity error. Some localized model instabilities existed and were largely associated at or near the pumping locations or weirs. Excluding the one calibration event for the Little Miami WWTP model $(-32 \%)$, the overall continuity errors, as reported in the EXTRAN output files, ranged from $-4.65 \%$ to $+1.82 \%$.

Between all seven WWTPs, the simulated peak flow rates varied between $-20 \%$ and $+38 \%$ from the observed values, and the median of the absolute percent differences was $8.5 \%$. The volume calibration differences varied from $-67 \%$ to $180 \%$, and had a median absolute percent difference of $20.5 \%$.

By including the WWTP hydraulics in the SWM, the downstream boundary condition has been effectively moved to the plant outfalls and the WWTP facilities have been simulated as model components. The model was developed to a level of detail to allow for planning purposes. Interactions between maximum hydraulic grade lines, collection system overflows, WWTP bypasses, and other components of an integrated WWTP/collection system 
model can be better studied. An integrated collection system and WWTP model is a tool that offers great flexibility and efficiency to explore their interaction under various wet weather flow conditions.

\section{Acknowledgments}

The authors wish to thank Ted Burgess, P.E. (CDM) for guidance on this project. The aerial photos of the wastewater treatment plants were made available from the Cincinnati Area Geographic Information System (CAGIS).

\section{References}

Huber, W. and Dickinson, R. (1992). Stormwater Management Model, Version 4: User's Manual, Environmental Research Laboratory, Office of Research and Development, U.S. Environmental Protection Agency, Athens, GA. 